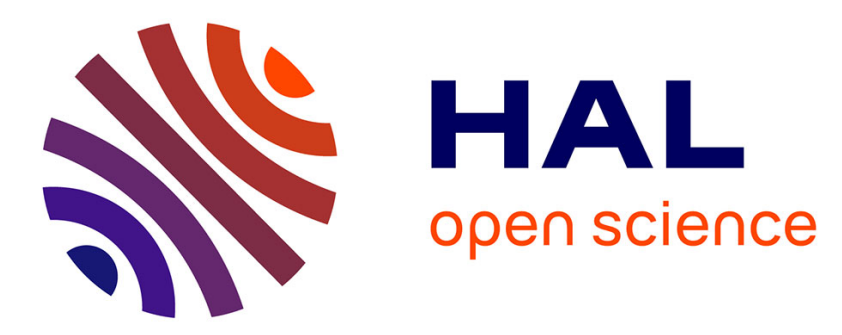

\title{
Distributed temperature sensing as a down-hole tool in hydrogeology
}

\author{
V.F. Bense, T. Read, Olivier Bour, Tanguy Le Borgne, T Coleman, Stefan \\ Krause, A. Chalari, M. Mondanos, F. Ciocca, J. S. Selker
}

\section{To cite this version:}

V.F. Bense, T. Read, Olivier Bour, Tanguy Le Borgne, T Coleman, et al.. Distributed temperature sensing as a down-hole tool in hydrogeology. Water Resources Research, 2016, 52 (12), pp.9259-9273 10.1002/2016WR018869 . insu-01403013

\section{HAL Id: insu-01403013 https://hal-insu.archives-ouvertes.fr/insu-01403013}

Submitted on 2 Jan 2017

HAL is a multi-disciplinary open access archive for the deposit and dissemination of scientific research documents, whether they are published or not. The documents may come from teaching and research institutions in France or abroad, or from public or private research centers.
L'archive ouverte pluridisciplinaire HAL, est destinée au dépôt et à la diffusion de documents scientifiques de niveau recherche, publiés ou non, émanant des établissements d'enseignement et de recherche français ou étrangers, des laboratoires publics ou privés. 


\section{Water Resources Research}

\section{REVIEW ARTICLE}

10.1002/2016WR018869

Key Points:

- Distributed Temperature Sensing in subsurface applications allows the monitoring subsurface hydrology in unprecedented spatiotemporal detail - The specific limitations of DTS measurements need to be taken into account in the design of field installations

- The application of DTS in subsurface hydrology is still under development

Correspondence to:

V. F. Bense,

victor.bense@wur.nl

Citation:

Bense, V. F., T. Read, O. Bour, T. Le Borgne, T. Coleman, S. Krause, A. Chalari, M. Mondanos, F. Ciocca, and J. S. Selker (2016), Distributed

Temperature Sensing as a downhole tool in hydrogeology, Water Resour. Res., 52, doi:10.1002/2016WR018869.

Received 1 MAR 2016

Accepted 14 NOV 2016

Accepted article online 18 NOV 2016

(C) 2016. American Geophysical Union. All Rights Reserved.

\section{Distributed Temperature Sensing as a downhole tool in hydrogeology}

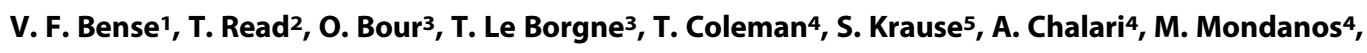 \\ F. Ciocca ${ }^{4}$, and J. S. Selker6
}

${ }^{1}$ Department of Environmental Sciences, Wageningen University and Research, Wageningen, Netherlands, ${ }^{2}$ School of Environmental Sciences, University of East Anglia, Norwich, UK, ${ }^{3}$ Geosciences Rennes, University of Rennes, Rennes, France, ${ }^{4}$ Silixa Ltd., Elstree, Hertforsdshire, UK, ${ }^{5}$ School of Geography, Earth and Environmental Sciences, University of Birmingham, Birmingham, UK, ${ }^{6}$ Biological and Ecological Engineering, Oregon State University, Corvallis, Oregon, USA

Abstract Distributed Temperature Sensing (DTS) technology enables downhole temperature monitoring to study hydrogeological processes at unprecedentedly high frequency and spatial resolution. DTS has been widely applied in passive mode in site investigations of groundwater flow, in-well flow, and subsurface thermal property estimation. However, recent years have seen the further development of the use of DTS in an active mode (A-DTS) for which heat sources are deployed. A suite of recent studies using A-DTS downhole in hydrogeological investigations illustrate the wide range of different approaches and creativity in designing methodologies. The purpose of this review is to outline and discuss the various applications and limitations of DTS in downhole investigations for hydrogeological conditions and aquifer geological properties. To this end, we first review examples where passive DTS has been used to study hydrogeology via downhole applications. Secondly, we discuss and categorize current A-DTS borehole methods into three types. These are thermal advection tests, hybrid cable flow logging, and heat pulse tests. We explore the various options with regards to cable installation, heating approach, duration, and spatial extent in order to improve their applicability in a range of settings. These determine the extent to which each method is sensitive to thermal properties, vertical in-well flow, or natural gradient flow. Our review confirms that the application of DTS has significant advantages over discrete point temperature measurements, particularly in deep wells, and highlights the potential for further method developments in conjunction with other emerging hydrogeophysical tools.

\section{Introduction}

Heat is widely recognized as an excellent tracer for a range of hydrogeological processes that can be inferred from temperature-depth measurements in boreholes [e.g., Saar, 2011]. The advantage of using heat over other tracers such as geochemical tracers is that heat is ubiquitous, economical, and easily measured in situ using a variety of probes and loggers with resolutions down to $10^{-3 \circ} \mathrm{C}[$ Pehme et al., 2013]. Near-surface (upper several $\mathrm{m}$ ) temperature measurements in either shallow piezometers or by pushing probes into the ground [e.g., Bense and exploiting the Kooi, 2004; Conant, 2004; Schuetz and Weiler, 2011] can be used to identify and quantify rates of groundwater-surface water interactions by exploiting the effect that groundwater upwelling or downwelling affects the propagation of the seasonal/diurnal temperature wave into the subsurface [Taniguchi, 1993].

At depths greater than $\sim 20 \mathrm{~m}$ seasonal surface temperature fluctuations can usually no longer be detected. Here the geothermal gradient mostly dominates temperature-depth profiles which are a function of both the local geothermal heat flux and thermal conductivity of the formation, primarily governed by Fourier's Law of heat conduction. Where a temperature-depth profile departs from this expected behavior, it is often indicative of groundwater flow which drives the advection of heat in addition to conduction. Temperaturedepth profiles can become convex or concave for upward for downward groundwater flow respectively [e.g., Bredehoeft and Papadopulos, 1965] while localized horizontal groundwater flow through fractures or faults often results in localized abrupt temperature changes that depart from the geothermal gradient [Ge, 1998; Bense et al., 2008]. 
The use of Raman-scatter based optical-fiber sensors to infer a spatial distribution of temperature along the fiber hosted in an enclosure (e.g., cable tubing), commonly known as Distributed Temperature Sensing (DTS) has seen a steep rise in popularity in studies of groundwater-surface water interactions [e.g., Selker et al., 2006; Briggs et al., 2012a; Hare et al., 2015] in which it forms an attractive alternative for conventional point temperature measurements [Bense and Kooi, 2004; Conant, 2004]. To a lesser extent, DTS has been deployed to evaluate hydrogeological conditions at depths below the seasonal zone (e.g., $>20 \mathrm{~m}$ ), which can only be accessed via boreholes (up to several $\mathrm{km}$ deep) or, in unconsolidated sediments, via directpush methods (up to $\sim 80 \mathrm{~m}$ ). The latter suite of applications will be the focus of this review.

This paper focuses on discussing the current state and range of options and techniques involving DTS technology in downhole settings to investigate groundwater hydrological conditions. After summarizing the principles of DTS with special attention to the relationship between resolution in space and time, we review the feasibility and limitations of DTS technology for groundwater studies in downhole applications.

\section{Principles of Distributed Temperature Sensing}

DTS uses the Raman backscatter characteristics of light emitted following a laser pulse into a fiber optic cable to determine the distributed temperature along fiber as long as $35 \mathrm{~km}$. Raman backscatter is generated by the inelastic interaction of the incident light with molecular vibrations in the fiber that causes the energy level of the emitted photons to be shifted up or down relative to the injected light [Rogers, 1999] (Figure 1). A measurement of the ratio of the intensity of photons returning at specific higher (anti-Stokes) and specific lower wavelengths (Stokes) in time allows for the calculation of the temperature along a fiber as a function of distance [Farahani and Gogolla, 1999; Hausner et al., 2011]. In most hydrological applications, DTS control units are used that determine distance via the transit time of backscattered light by exchanging time for distance, under the same principles as an optical time domain reflectometer (OTDR) [Dakin et al., 1985]. In an alternative implementation, DTS systems can also be based upon optical frequency-domain reflectometry (OFDR) [Bolognini and Hartog, 2013]. Both OTDR and OFDR techniques use the fiber itself as a continuous sensing element that is interrogated over a certain distance of cable.

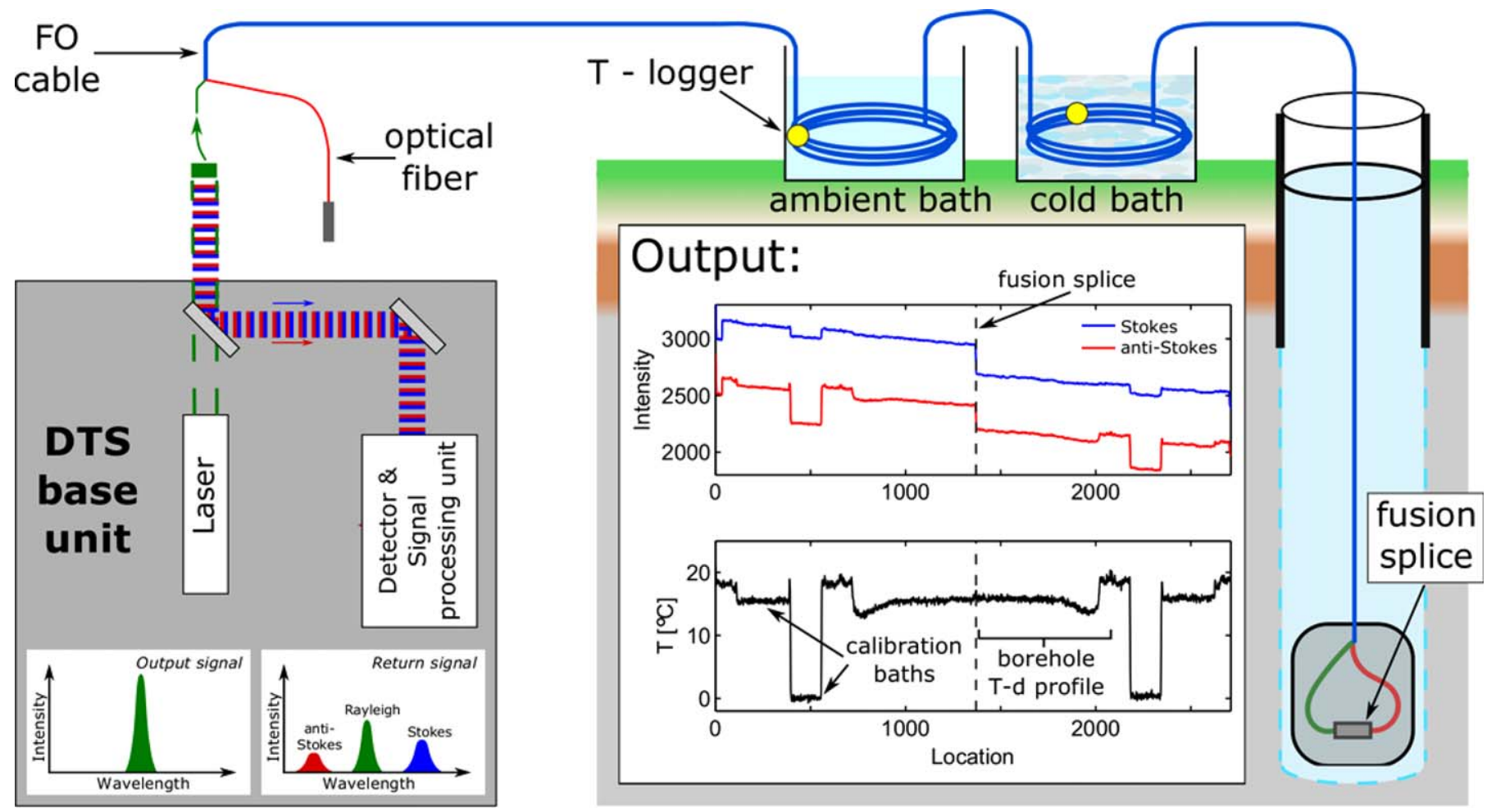

Figure 1. Schematic of DTS principles based upon Raman backscatter detection. In this cartoon, a fiber-optic cable is deployed in a duplexed single-ended setup. A double-ended measurement would be possible by additionally connecting the red optical fiber to the instrument, and alternating measurements between the two instrument channels. 
Alternatively, at point locations the fiber Bragg gratings (FBG) may be etched into the fiber which allows to obtain a temperature at point locations [Guan et al., 2013]. To discuss the specifics and potential disadvantages and advantages of these DTS techniques (OTDR/OFDR-based, or using FBGs), and other possible approaches (e.g., the use of different wavelengths for the emitted light) goes beyond the scope of this review.

\subsection{Temperature Calibration and Monitoring Modes}

After sending out high-frequency laser pulses, a DTS instrument analyses the Stokes and anti-Stokes intensities integrated over user specified time and spatial intervals along the cable. From these data, the average temperature for each increment of length along a fiber optic cable is calculated using three calibration parameters. Values for these calibration parameters are typically obtained by use of an instrument-internal reference coil of fiber in combination with internal and external temperature probes attached to the DTS unit. However, light loss (e.g., from fiber damage or where it has been spliced) at any location along the path can result in abrupt offsets in computed temperature along the cable which values easily exceed $\pm 1^{\circ} \mathrm{C}$. Much more precise and accurate temperatures (in the order of $0.02^{\circ} \mathrm{C}$ ) can be obtained through use of external reference temperature baths [Tyler et al., 2009], and postprocessing of the observed Stokes and anti-Stokes data to calculate temperature values [Hausner et al., 2011; Van De Giesen et al., 2012]. These reference baths must create homogeneous temperature conditions, which need to be constant over the measurement integration time, in which lengths of fiber optic cable of for example at least 10 times the sampling interval, and fully external reference temperature loggers are installed [Hausner et al., 2011; Van De Giesen et al., 2012].

Ideally, calibration is based upon at least three externally measured temperatures taken along each section of fiber (i.e., between locations of splices or connectors), two of which must be separated in space. When there are three locations with known temperatures (e.g., water baths in which temperatures are constantly homogenized), but a splice or damage exists at a location in between, it is possible to correct the ratio of the Stokes and anti-Stokes intensities to account for the differential attenuation occurring at this point [Hausner and Kobs, 2016]. The two general configuration options for the optical path of the fiber are known as single-ended and double-ended configurations, and cables may be produced as simplex or duplex (i.e., with either one or two fibers in the same cable) each of which presents specific options for calibration. Generally speaking, duplexed and double-ended cable set-ups allow for more accurate calibration since multiple measurements are then taken at each location along the cable. In borehole deployments, any of these options may be appropriate and are outlined briefly here.

In a conventional single-ended set up, a single fiber is coupled to the base unit and terminated at the other end. This cable can be looped back in and out of a borehole [Read et al., 2013] in which case in principle the temperature-depth profile should be symmetrical around the downhole turn-around point. If the fibre loop is constructed within a single cable tube by connecting two fibers at the remote end, this would be called a duplexed installation. In either case, the looped setup and the consequent symmetry of the measurement can be used to depth locate the observed temperatures (Figure 1). Duplexed cables do present certain potential issues. First, the splice at the end of the cable must be protected, which in the case of deep boreholes, can require a high-pressure resistant enclosure. Further, the data after the splice need to be adjusted for potential differential loss of the return signals at the fusion splice [Hausner et al., 2011]. Additionally, such splices can generate spatially distributed defects in temperature measurement, which can be challenging to detect and correct for [Arnon et al., 2014a].

Double-ended installations are those where the optical path of the fiber both begins and ends at the DTS, so that light might be passed in both directions along the fiber. Measurements are taken alternately from each instrument channel, which are referred to as the forward and reverse directions [Van De Giesen et al., 2012]. In this way, it is possible to compute calibration parameters for each section of the fiber to adjust for nonuniform differential attenuation along the cable occurring at bends, connectors, splices, and where there has been fiber degradation (e.g., hydrogen ingress). The key point here is that the calibration strategy is dictated by the fiber layout, and must be considered in detail as part of the experimental design.

\subsection{DTS Performance Metrics}

The key metrics of DTS system performance are the accuracy and precision of reported temperature, at the specified spatial resolution and integration time. The uncertainty in temperature is typically characterized 

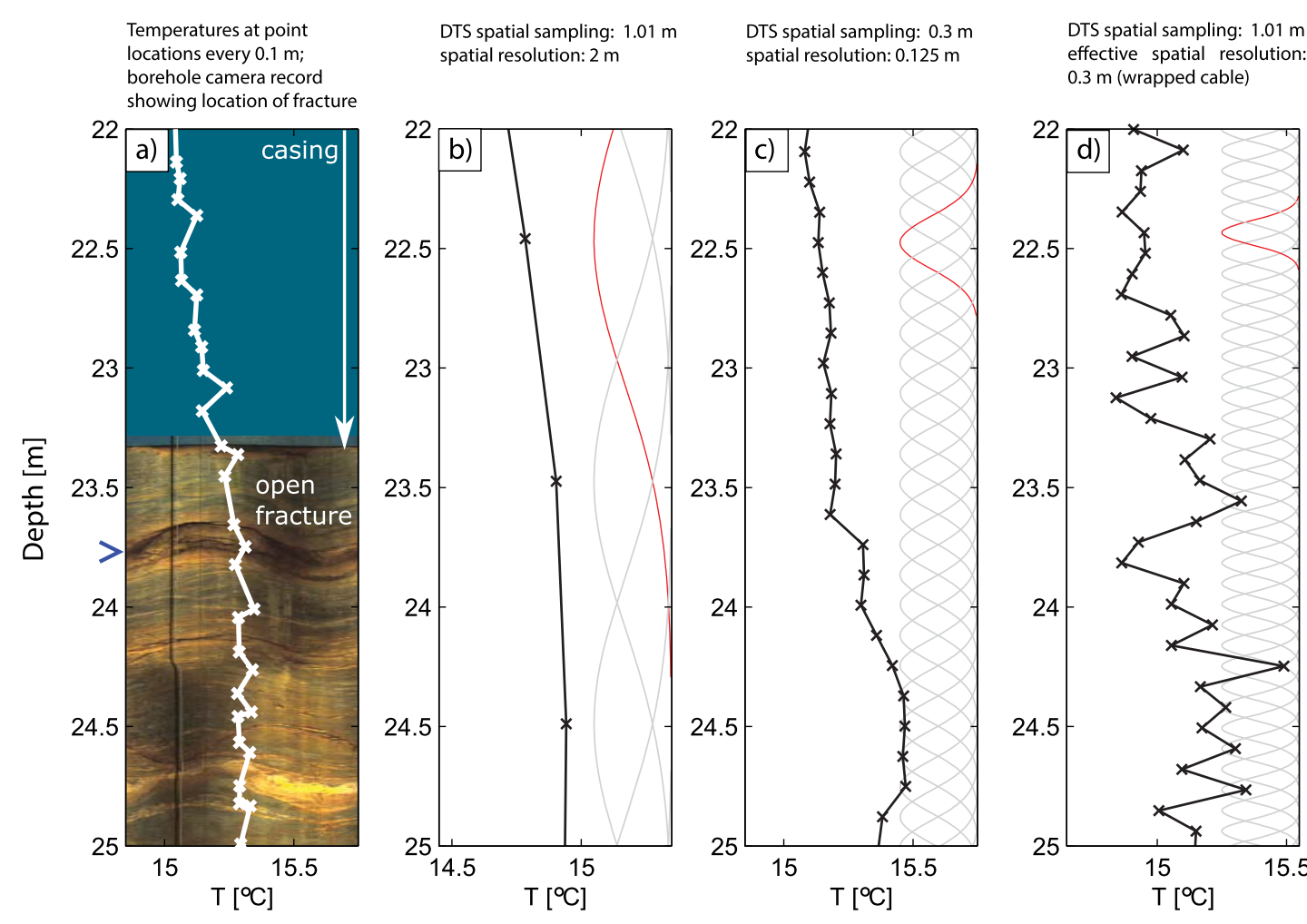
DTS spatial sampling: $0.3 \mathrm{~m}$ effective spatial resolution $0.03 \mathrm{~m}$ (wrapped cable) $0.3 \mathrm{~m}$ (wrapped cable)

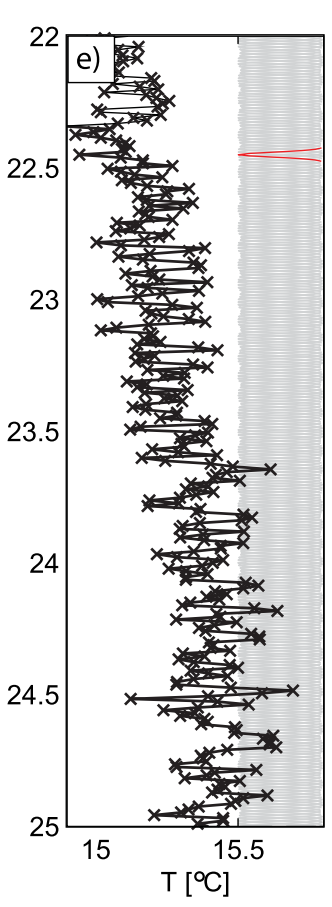

Figure 2. Section of a temperature-depth profile collected in an open well at the Ploemeur research site, France, showing (a) optical televiewer and temperature-depth profile measured with a high precision temperature probe measuring every $0.1 \mathrm{~m}$, (b) $2 \mathrm{~m}$ spatial resolution $(1.01 \mathrm{~m}$ spatial sampling) instrument with a standard cable, (c) $0.3 \mathrm{~m}$ spatial resolution ( $0.125 \mathrm{~m}$

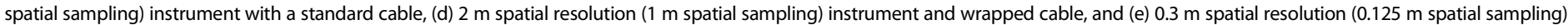
instrument and wrapped cable. Each DTS temperature-depth profile is a $10 \mathrm{~min}$ time average collected on the same day. Gray curves (one highlighted in red) show the Gaussian spatial weighting function for each DTS-reported temperature measurement along the cable (marked with x's in the plots), calculated using the method given in Selker et al. [2014].

by the standard deviation or root-mean-square error (RMSE) of the reported temperature in comparison to the true temperature. The RMSE in temperature normally scales with the square root of the product of the integration time and the length of cable over which the temperature is being reported. This reflects the central limit theorem applied to the number of photons employed in the intensity estimates. The RMSE is also a function of distance along the cable due to Beer's Law attenuation of light with travel distance from the base unit, with data further from the instrument having lesser accuracy. The relationship between RMSE and distance is more complicated in the case of double ended measurements, wherein reported temperatures are computed using light traveling in both directions along the cable. For double-ended installations, the lowest RMSE occurs at the midpoint of the cable equidistant from the base unit along each channel.

DTS units can be set to report back temperatures at a range of sampling intervals, wherein the spatial resolution is always at least twice this value according to the Nyquist theorem [Selker et al., 2014]. The limiting spatial resolution of a DTS is determined at a step change in temperature along a cable, and is defined as the distance between the points, for example, at $10 \%$ and $90 \%$ of the true temperature change [Tyler et al., 2009; Selker et al., 2014]. Putting these concepts together lead DTS manufactures to report measurements the less than half of the limiting spatial resolution. Each reported Stokes and anti-Stokes backscatter intensity, and hence the calculated temperature, at a specific distance is an average weighed by a Gaussian function along the sampling interval (Figure 2). When discussing temporal resolution we mean it to be the ability to detect temperature change in time. The temporal resolution of an measurement configuration is limited by a combination of the performance of the DTS instrument and thermal inertia of the cable used. In groundwater systems, temperatures are only slowly changing naturally at a rate well within the temporal resolution of any DTS system, however in A-DTS configurations temperatures will be changing at a much higher rate and the temporal resolution of the system used will need to be considered more carefully [e.g., Read et al., 2014]. Modern DTS systems typically can sense temperature distributions along the entire cable every few seconds. Hence, cable thermal properties are commonly the most significant factor in thermal 
responsiveness. Larger diameter and more massive cables of high thermal inertia respond more slowly to ambient temperature changes. As long as data storage is not a limiting factor, it is usually advisable to set the spatial and temporal averaging to the highest possible frequency the instrument supports, since internal averaging applied by the instrument cannot be subsequently undone. Typically postprocessing averaging provides all the advantages which would be obtained from longer collection intervals. This should be confirmed for each DTS base unit as we know of one manufacturer employs methods that violate this assumption wherein there is a penalty to selecting high temporal and spatial resolution. In all cases, data collected at high frequency can lead to unwieldily data sets (e.g., from a long cables and long-duration installations). Furthermore, on some instruments data can be recorded faster on the instrument than it can be downloaded, resulting in the memory limit of the instrument eventually being reached.

\subsection{Cable Selection and Installation}

In shallow wells, it is typically possible to install a fiber-optic cable by spooling it off into the well to the desired maximum depth and left to monitor temperature. In deeper wells the feeding of the cable into the entrance of the well may need to be addressed to support the weight of the cable and limit bending radii. Fiber optic cables must be protected from damage due impact from pumps or colocated instruments. In deep wells fiber optic cables are often installed in the cement behind the borehole casing where they are nonreplaceable. So-called pump down systems are commonly used in oil and gas applications [Smolen and van der Spek, 2003], but not so in hydrogeology. These use a small diameter open tube sitting inside the borehole in which a fiber-optic cable can be led down and replaced if necessary after deterioration of the fiber over time for example after prolonged exposure to high temperatures in a geothermal heat production or oil well.

Short-range DTS units (under $10 \mathrm{~km}$ ) generally use multimode fibers (typically $50 \mu \mathrm{m}$ core diameter, 125 $\mu \mathrm{m}$ cladding diameter). The added glass cross section allows injection of greater light intensity, and captures a larger fraction of the backscatter compared to single-mode fibers, which results in higher measurement performance. Cable design that includes multiple fibers are advisable for downhole applications as these provide redundancy in case of damage occurring to one, and allows single-ended or double ended measurements to be obtained (Figure 1).

Every fusion splice needs physical protection. Above ground splice protection is primarily against movement of the fiber and exposure to water. Downhole splices must be protected against pressure using specially designed enclosures, sometimes potting the splices in rigid resin. The entire fiber must be protected pressure which can cause nonuniform differential attenuation. Fibers are often hermetically sealed into rigid (plastic or stainless steel, depending on required pressure rating) capillary tubes. Since the fiber must be completely protected from mechanical stress, the fibers path within the capillaries is helical to accommodate slight changes in the cable length if it is put under tension or experiences significant temperature changes. This results in an optical path that is about $0.5 \%$ longer than the cable. For sites that may contain organic compounds, the cable design should include hydrogen-scavenging gel. Further protection from hydrogen ingression is obtained by encasing the stainless steel capillary tube in aluminum, which has much lower gas permeability [Reinsch et al., 2013]. Additional crush resistant armoring, tensile elements, and an abrasion resistant plastic jacket may be needed. Selection of jacket material also must accommodate any markings needed, such as distance increments. In downhole applications, cables require sufficient tensile strength to support their own weight over the depth of the deployment without transferring stress to the fiber.

In borehole installations, it is generally advantageous to seek the highest spatial resolution possible. This will enhance the prospect to resolve individually, for instance, closely spaced fractures that carry groundwater flow. As stated above, for most DTS systems, should lower spatial resolution be found to be sufficient, the data may be averaged in postprocessing with no loss in performance relative to having obtained the data at lower spatial resolution from the outset. Averaging of high spatial resolution data may be appropriate when carrying out heat pulse tests in settings where the geology is known to be relatively homogeneous of large depth intervals. In fractured aquifers, where fracture flow may cause localized cooling, averaging high spatial frequency data into a lower spatial frequency composite may completely average out this response. One may achieve a desired spatial resolution either by selecting an instrument with the desired spatial resolution, or, a wrapped cable can be deployed [Hilgersom et al., 2016]. In such a cable, the 
optical fiber is wrapped around a central strength member, such that for every unit length of cable there is a greater length of optical fiber, so the effective spatial resolution is increased. Custom made solutions have been used to measure shallow temperatures with depth in glaciers and lakes [Selker et al., 2006], and stream bed sediments [Briggs et al., 2012b; Vogt et al., 2010], while prewrapped cables can also can be purchased and have been deployed in lakes [Arnon et al., 2014a], and boreholes [Banks et al., 2014]. Data from wrapped cables need careful processing. In the case of tightly wrapped fibers, there have been documented entrance effects in approximately the first $100 \mathrm{~m}$ of fiber after the transition from a straight cable to wrapped cable that if not corrected for, will result in erroneous data [Arnon et al., 2014a]. Because of the distance and time varying nature of the correction, Arnon et al. [2014b] developed an empirically based method for the processing of wrapped cable data.

To illustrate the various spatial averaging options, it is useful to look in detail at a short $3 \mathrm{~m}$ section of a borehole at the Ploemeur research site, France, using different combinations of instruments and cables (Figure 2). Data were collected by instruments with manufacturer specified spatial resolutions of 2.0 and $0.3 \mathrm{~m}$ (sampling at 1.01 and $0.12 \mathrm{~m}$, respectively) on standard (Figures $2 \mathrm{~b}$ and 2c), and wrapped cables (Brugg High Resolution cable, Brugg, Switzerland, Figures $2 \mathrm{~d}$ and $2 \mathrm{e}$ ). An open fracture was encountered at a depth of $23.8 \mathrm{~m}$ depth, providing an outflow for groundwater which flowed up the borehole. In such scenario a change of the thermal gradient at the location of the fracture would be expected which could be used to infer the rate of inflow at the location of the fracture [Klepikova et al., 2014]. However, in this example the impact on the temperature gradient of this outflow is very subtle, but detectable, as is apparent from the point temperature measurements shown in Figure 2a. Data from the $2 \mathrm{~m}$ spatial resolution instrument and straight cable would give the impression of a relatively smooth temperature-depth profile and is unable to detect the change in gradient. In this case, the $2 \mathrm{~m}$ Gaussian spatial weighting of each temperature measurement spans the cased, rock, and fractured rock intervals, rendering these features indistinguishable. In contrast, the $0.3 \mathrm{~m}$ spatial resolution instrument with the straight cable (Figure $2 \mathrm{c}$ ) allows identification of the location and quantification of the step temperature change at the fissure, and would provide an improved characterization of the change in gradient over the point measurements (Figure 2a). Wrapping the cable to enhance the spatial resolution in combination with either low-res or high-res DTS instrument (Figures $2 \mathrm{~d}$ and $2 \mathrm{e}$ ) does not seem to result in a detection of the changing gradient at the location of the fracture. This is probably because as a result of the wrapping greater noise is introduced in the data due to the Beer's law light loss along the additional optical path length, and further from light loss that occurs at bends. The effective spatial averaging in Figure $2 \mathrm{~d}$ ) is similar to Figure $2 \mathrm{c}$ ), but for the latter reason, the temperature resolution is lower. Pairing the $0.3 \mathrm{~m}$ spatial resolution instrument with the wrapped cable gives an effective spatial resolution of $0.03 \mathrm{~m}$, which is now comparable to the spatial extent of the fractures but still the change in temperature gradient is hardly visible at the location of the fracture (at a depth of $23.8 \mathrm{~m}$ ). Concluding in this installation only one DTS configuration was successful in detecting the fracture flow process of central interest in this study. This example shows the care required to effectively employ DTS. It is advisable to pretest the design of the field installation, choice of DTS, and cable configuration.

\section{DTS Monitoring in Passive Mode}

DTS measurements are termed "passive" if there is no active heating of the cable itself or in the DTS monitored well. In piezometers or cased boreholes, it can sometimes be assumed that the temperature measured in the fluid at a given depth is the same as the temperature in the formation. In open or long screened boreholes, this is often not the case. The inflow of water with different temperature to the resident water causes small inflections in the temperature-depth profile and is useful to identify hydraulically active fractures [Drury et al., 1984]. For large inflows of distinctly different temperature, or in the case of warmer water entering below cooler water, the temperature signal may advect through the well. This temperature signal may allow the flow to be estimated using analytical [Drury et al., 1984], or numerical modeling approaches [Klepikova et al., 2011].

DTS has been used to measure temperature-depth profiles in the subsurface in a variety of settings. Grosswig et al. [1996] monitored seasonal temperature changes in the subsurface at a waste disposal site. They also detected a warm temperature signal just beneath the zone of seasonal fluctuation, attributed to exothermic reactions in surrounding waste material. DTS has also been used to assess lithological changes 
from passive temperature data in boreholes assuming that changes in temperature gradient reflect variations in thermal properties coupled to lithology [Foerster et al., 1997; Wisian et al., 1998]. Foerster et al. [1997] concluded that DTS was suitable for studies of terrestrial heat flow, but had a temperature resolution 5-10 times less than their conventional logging approach. However, we note that current instruments would be able to significantly improve on the latter result. Henninges et al. [2005] used a similar approach to Foerster et al. [1997] and Wisian et al. [1998] in an area of permafrost, and quantified thermal properties with depth by assuming a uniform vertical heat flow density. The distinct advantage of using DTS in this setting is that the cable can be installed immediately after drilling or incorporated into the well construction [Henninges et al., 2003], when refreezing of the hole would prevent access to logging devices [Hurtig et al., 1996]. Stotler et al. [2011] also make use of DTS to monitor permafrost and subpermafrost temperature conditions.

There has been renewed interest in carrying out thermal tracer tests, with passive temperature monitoring in a number of observation wells [Wagner et al., 2014]. This may be stimulated by the desire to directly study heat transport in the subsurface, or to use temperature as an easily monitored tracer for groundwater flow. The advantage of using DTS here is that multiple observation wells can be monitored simultaneously using the same instrument, either by using multiple cables attached to the same instrument, or by using one continuous cable that is looped inside each borehole [e.g., Read et al., 2013]. Thermal tracer tests monitored using DTS have been carried out in a variety of settings including: a sedimentary aquifer [Macfarlane et al., 2002]; a fractured sandstone [Hawkins and Becker, 2012]; a fractured granite [Read et al., 2013]; and a shallow sedimentary aquifer [Hermans et al., 2015]. Recently, Bakker et al. [2015] carried out a thermal tracer test monitored with DTS without monitoring wells using fiber optic cable in the subsurface installed by direct push. In unconsolidated sediments, this approach allows thermal tracer tests to be monitored economically, in detail, and with minimal disturbance to the aquifer.

\section{DTS Monitoring in Active Mode (A-DTS)}

In A-DTS, the cable [e.g. Read et al., 2014; Coleman et al., 2015; Hausner et al., 2015], borehole fluid [e.g., Leaf et al., 2012; Read et al., 2015], or surrounding rock formation is heated [Bakker et al., 2015]. The temperature response at some or all points during this process is then indicative of either the lithology, ambient groundwater flow, or in-well flow, and depends closely on how the cable is deployed in the borehole and the nature of the thermal disturbance. These issues are the subject of this section. We have categorized the various current A-DTS methods in Figure 3. These are thermal advection tests (Figure 3a), hybrid cable flow logging (Figure $3 b$ ), and heat pulse tests (Figure 3c). Figure 3 shows typical cable setups, heating locations, and data, for a well intersecting two fractures with additional layered heterogeneity. We assume that in this well ambient flow (fracture flow freely entering the uncased borehole) or pumping occurs (Figures $3 a$ and $3 b$ ). Alternatively, there exists fracture flow in the formation but this flow is not entering the well (but flowing around it) due to the presence of a casing or by use of a liner (Figure 3c). Each of these three principal methods is outlined in turn in the following sections.

There are two principal strategies that have been trialed in hydrogeology to introducing a thermal anomaly along the DTS cable in the subsurface to enable an A-DTS measurement. These are the physical injection of a fluid (usually water) with a contrasting temperature into the system, or the use of electrical heating techniques. In oil and gas applications chemical pills have been used to create thermal anomalies in boreholes [Edwards et al., 2010] which is a method that has not been used in hydrogeological applications as far as we are aware.

Injection of fluid with a contrasting temperature may be carried out at a single location and for a short period of time to create a discrete plume in the borehole [Leaf et al., 2012]. Alternatively, the injection may be carried out over a longer period to replace the fluid in a longer section of the borehole with fluid warmer or colder than the surrounding rock [Yamano and Goto, 2005; Read et al., 2013]. A second way to create a thermal anomaly is to use electrical conductors within the DTS cable used for measurements to create a heating circuit, a separate heating cable or heating elements. Electrical heating techniques offer several advantages over injecting a fluid. The use of electrical heating does not disturb ambient vertical flows of which there is a great risk during fluid injection into the borehole as described above. Electrical techniques make it also easier to quantify the amount of heat added to the system that can be readily calculated by integrating the input power over time. 
a)

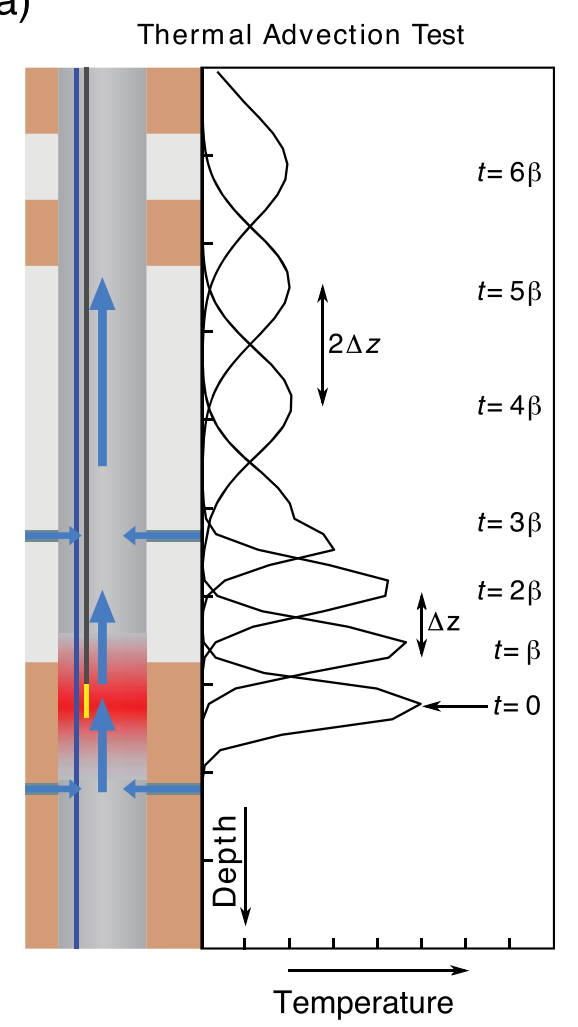

Power cable (non-heated)
DTS cable b)

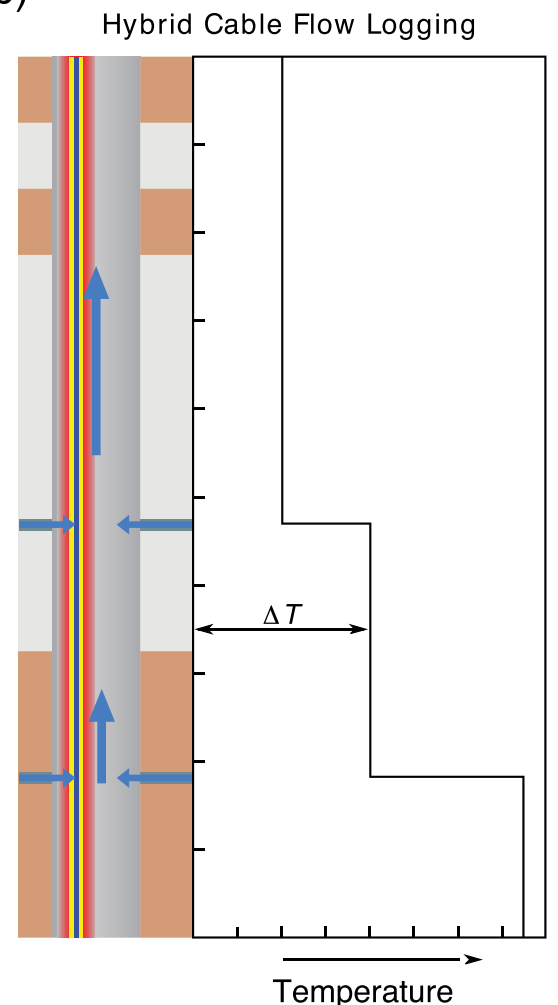

Heating cable/element

Combined ('hybrid') heating/DTS cable c)

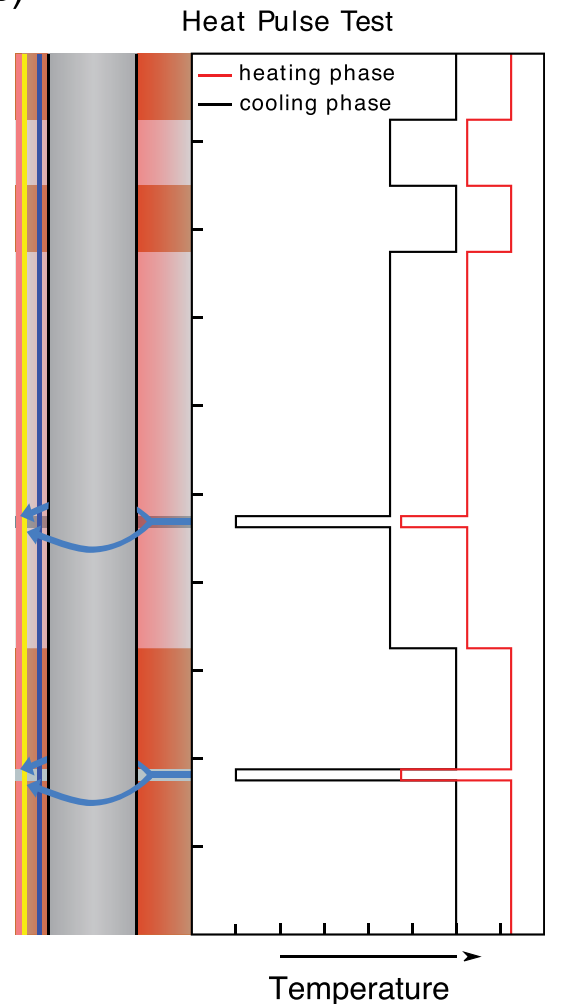

Fluid flux towards and in the boreohle. In case of (c) fluid flow is around the cased borehole

Figure 3. Schematic of three Active-DTS methods in a well intersecting two discrete transmissive zones (e.g., fractured intervals) and varying lithology. Right-hand side plots in Figures $3 a-3 c$ show the diagnostic data to be observed for each test. (a) Thermal advection test with temperature-depth profiles after point injection or point heating resulting in a quantifica-

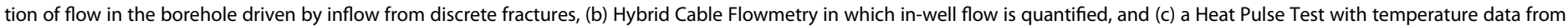
the heating and cooling phase as observed outside the borehole either by using a liner [e.g., Leaf et al., 2012] or by installation of DTS cables in a borehole casing grout, or via direct-

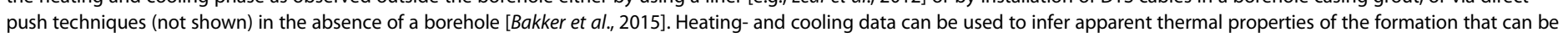
related to both heat-advection (groundwater flow) and heat-conduction in the formation. See the text on each method for further detail.

Electrical heating can be carried out along the entire or part of the length of the borehole or at point locations. Point heating can be achieved using small heating elements [Sellwood et al., 2015a; Read et al., 2015]. Uniform heating over lengths of borehole can be achieved with Joule heating along an electrical conductor [Kurth et al., 2013]. It is possible to directly heat the same cable used for DTS temperature monitoring by driving electrical currents through metallic armoring provided that an electrical connection is available to both ends of the cable [e.g., Sayde et al., 2015; Read et al., 2014], utilizing a composite cable design that incorporates parallel electrical conductors and optical fibers [Coleman et al., 2015], or by ad hoc solutions that involve the manual wrapping of a passive DTS cable around a line source of heat [Liu et al., 2013; Seibertz et al., 2016]. Specifically designed and manufactured cables are typically required since standard cable jackets may not be designed to be safe at elevated voltage. Electrically insulated heating elements inside the same cable construction can be more economical, however, the geometry is not radially symmetric, and small differences in the separation between the heating element and optical fibers may cause temperature anomalies observable during heating. Even with a radially symmetric cable, there may still be longitudinal differences in heating [Cao et al., 2015]. For heated cable methods, the power output from the heated cable, $P[\mathrm{~W}]$ can be calculated according to $P=V I$, in which $V$ is the voltage drop along the cable $[\mathrm{V}]$, and $I[\mathrm{~A}]$ is the electrical current. If constant power output through time is required, an active power controller is needed to supply constant total power (due to the temperature dependent resistance of conductors). The total power output can then be divided by the length of the heated section to obtain the heat generated per meter of cable. In downhole applications, power inputs in the order of 5-20 W/m have been used successfully. 
However, the power input to be applied in any specific A-DTS application to generate the most informative data set would vary with parameters such as borehole radius, potential for generating thermal convection inside the borehole, and the temporal and spatial resolution of the DTS measurement configuration.

Since with A-DTS experiments a thermal anomaly (positive or negative) is introduced into the system, there is the possibility that water viscosity and density will be affected to the degree that convection is induced in the system. When this occurs such effects will need to be included in the interpretative framework of the A-DTS data set. However, relatively simple calculations, for example using Rayleigh number analysis, can give already an indication of how important convection might be in a given system [Read et al., 2015]. Hence, an A-DTS configuration might be designed to minimize the complications arising from such effects.

\subsection{Thermal Advection Tests}

Thermal advection tests have been deployed to determine the location and significance of inflows and outflows from wells. In general, the principle is that the introduction of water with an anomalous temperature is tracked as it moves vertically in the well (Figure 3a).

The most common form of this method uses a point source to generate a heat pulse. In point heating experiments, the movement of a packet of either warmer or cooler water in the well bore is tracked using DTS. If dispersion can reasonably be assumed to be symmetrical, then the movement of the temperature peak (or minimum) will be representative of the cross-sectionally averaged velocity. The test is carried out with a fiber optic cable installed in the borehole fluid. The point heating approach is possible with either the injection of fluid [Leaf et al., 2012], or with point electrical heating [Sellwood et al., 2015a, 2015b; Read et al., 2015]. For fluid injection, a thermally insulated hose is lowered down to the depth of interest and fluid pumped or allowed to drain in from the surface. Point electrical heating makes use of a submersible electric heater lowered down to the target depth. The aim of both approaches is then to create a short section of the borehole with anomalous temperature water that can then be tracked with DTS. Qualitative analysis of the DTS data obtained allows the local flow characteristics to be inferred, for example, the identification of vertical flow and the flow direction. Quantitative analysis involves calculation of vertical flow rates from the displacement of plume

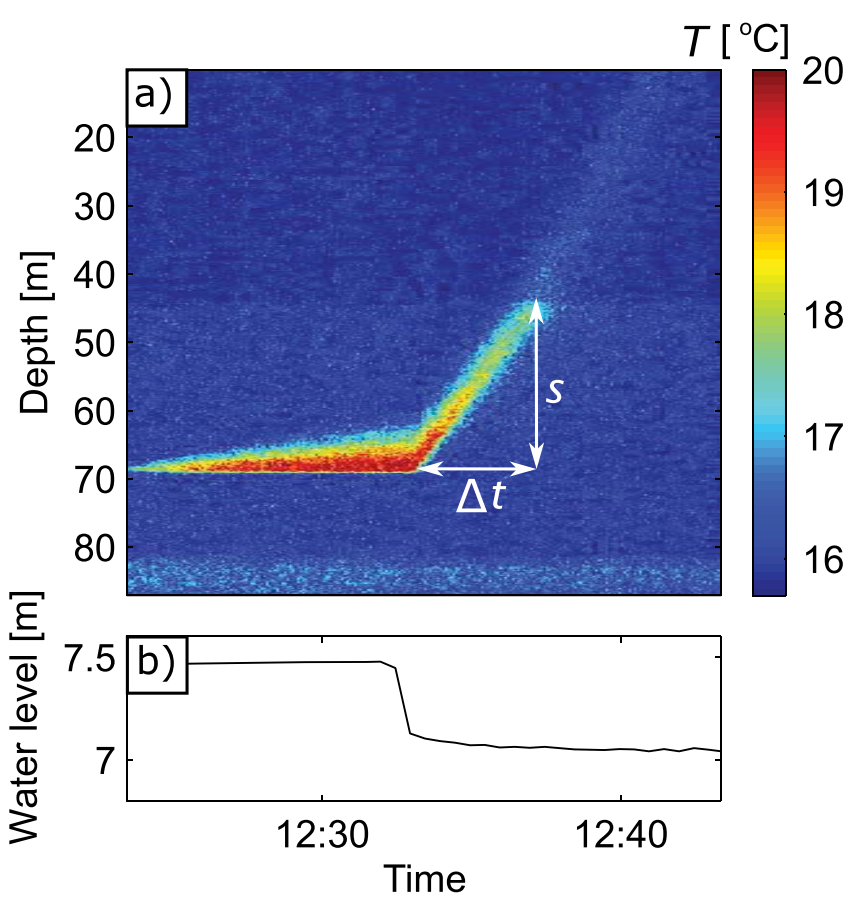

Figure 4. Electrical point heating experiment carried out in a well with ambient vertical flow, then stimulated by pumping (adapted from Read et al. [2015]), showing (a) DTS measured temperature showing the distance $(s)$ travelled (upward in this case) by the thermal anomaly introduced at the point heating element within a certain time interval $(\Delta t)$. The water velocity in the well is given by $s / \Delta t$. (b) The water level in the well during the test. Pumping was initiated at 12:33. peaks between successive DTS temperature profiles [e.g., Read et al., 2015].

Figure 4 shows a point heating experiment carried out in a borehole penetrating a sparsely fractured aquifer, adapted from [Read et al., 2015], where it is referred to as the Thermal-Plume fiber Optic Tracking (T-POT) method. Here a point heater, at a depth of $68 \mathrm{~m}$, generated a localized region of warmer water. Heating was switched off, and pumping at shallow depth simultaneously began, advecting the plume upward. Assuming no significant heat loss from the bore to the formation, tracking the plume peak allowed the upward fluid velocity in the borehole to be calculated at $11.3 \mathrm{~cm} \mathrm{~s}$. Through a series of controlled tests, Sellwood et al. [2015b] showed that thermal advection tests can be used to measure velocities down to below $0.06 \mathrm{~cm} \mathrm{~s}^{-1}$. If the vertical flux to be measured is high, then injecting fluid may be acceptable. However, if attempting to measure very low velocities, then fluid injections are likely to 


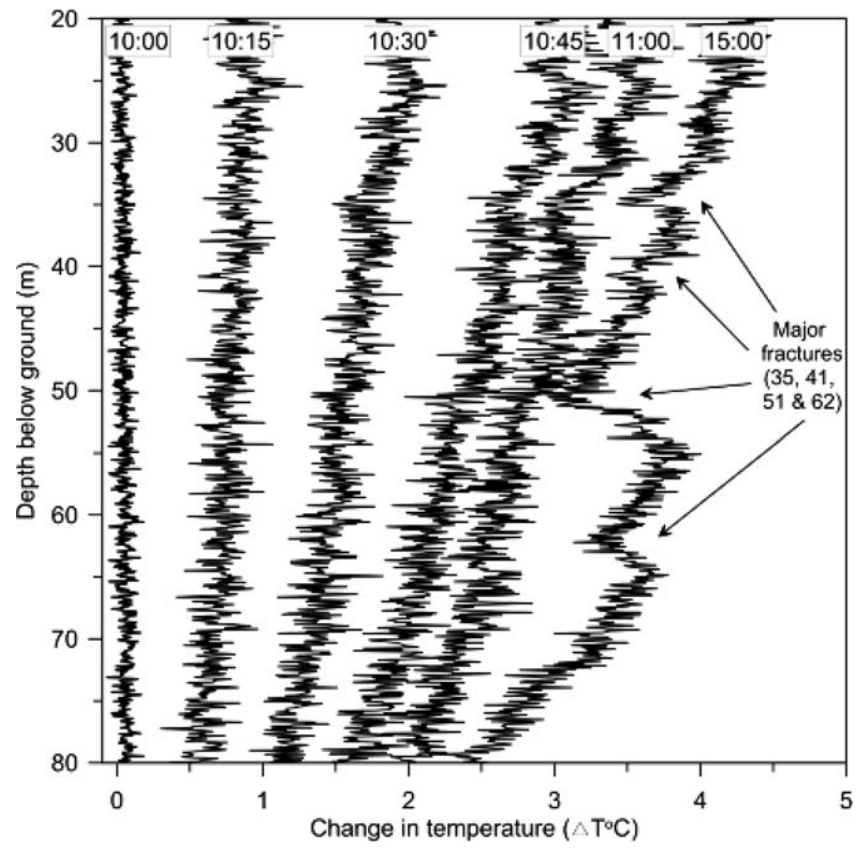

Figure 5. Schematic response after heating (10:15-11:00) an open borehole with separate heating cable in both ambient conditions and then during pumping (at time 15:00), taken from Banks et al. [2014]. disturb the hydraulic head in the well and therefore the velocity itself. In such conditions, point electrical heating would be preferable. In an oil and gas reservoir setting, Rahman et al. [2011] have carried out similar point heating experiments in-well bores.

A variant of this method is to heat or inject at a point continuously. The result is a front of warm or cold water that propagates vertically through the well. This has been applied mainly in deep [Yamano and Goto, 2005], and geothermal wells [lkeda et al., 2000; Sakaguchi and Matsushima, 2000]. In such tests, the spacing of the front as it vertically propagates can be used to locate inflows and outflows. Additionally, the analytical solution presented by Yamano and Goto [2005] allows the temperature-depth profile, following prolonged injection of water at the surface, to be inverted for flow.

A third variant is to use a distributed, rather than point heat source. This was carried out by Banks et al. [2014] using a heating cable and a wrapped high spatial resolution fiber optic cable separated by a fixed distance. Figure 5 shows DTS temperature data obtained prior to heating, during heating, and then after pumping was initiated at the top of the borehole. Once pumping was started, the inflowing fractures caused step-like reductions in fluid temperature. As suggested by Banks et al. [2014], it may be possible to derive a flow log based on the gradients of the temperature-depth profile between fractures, and the size of the temperature anomalies arising. While this method is not as simple as the point method for velocity estimation, it has the advantage that the entire borehole can be evaluated simultaneously.

\subsection{Hybrid Cable Flow Logging}

In-well vertical flow may also be monitored with hybrid cable flow logging. In this method, heating occurs within the same cable as the optical fibers, and the cable is deployed in a well in contact with flowing groundwater (Figure $3 b$ ). The principle is that when the cable is heated with a constant power input over time, the temperature inside the cable at steady state is a function of the velocity of the surrounding water. Higher velocities reduce the cable temperature by more effectively thinning the thermal boundary layer in the fluid around the cable. This method has also been used to estimate wind speeds [Sayde et al., 2015] and seepage through dams [Aufleger et al., 2007]. Read et al. [2014] show that for a typical armored cable with radial symmetry, the temperature difference between the cable center and water temperature $\Delta T$ is given by:

$$
\Delta T=\frac{Q}{2 \pi}\left(\frac{1}{h r_{2}}+\frac{1}{k_{c}} \ln \frac{r_{2}}{r_{1}}\right)
$$

where $Q\left[\mathrm{~W} \mathrm{~m}{ }^{-1}\right]$, is the heat input to the cable, $h\left[\mathrm{~W} \mathrm{~m}^{-2} \mathrm{~K}^{-1}\right]$, is the heat transfer coefficient, $r_{1}$ is the radius of the armoring, $r_{2}$ is the total cable radius, and $k_{c}\left[\mathrm{~W} \mathrm{~m}^{-1} \mathrm{~K}^{-1}\right]$, is the thermal conductivity of the insulating material between $r_{1}$ and $r_{2}$. In practice, it is difficult to calculate $h$ from first principles, however it can be readily found empirically by taking measurements at a number of known flow velocities during a field test [e.g., Read et al., 2014], or could be inferred from controlled laboratory experiments.

Figure 6 shows values of $\Delta T$ collected in a pumped well from the data set collected by Read et al. [2014], with a velocity profile obtained with an impeller flowmeter for comparison. The hybrid cable method identified step changes in flow from inflowing fractures that appeared as step reductions in the $\Delta T$. The 


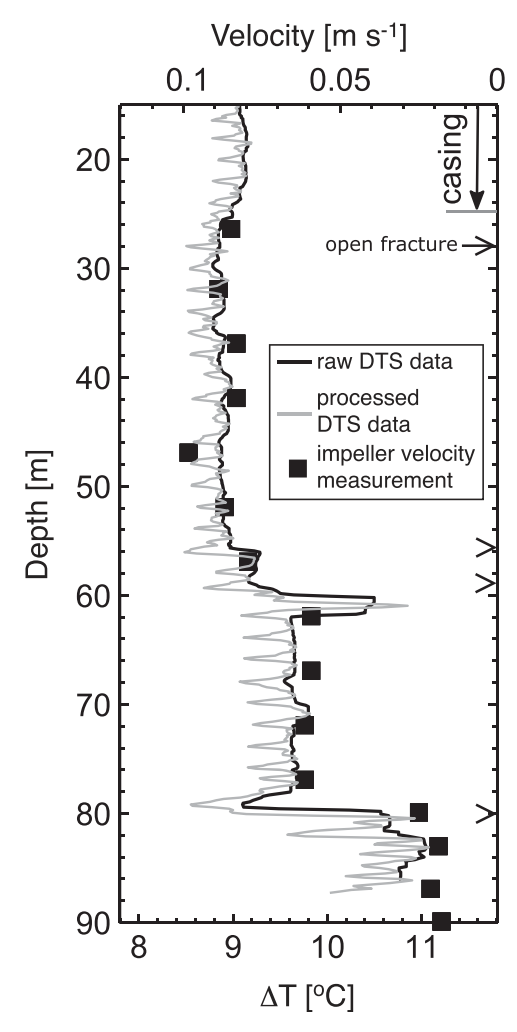

Figure 6. Comparison of $\Delta T$ profile and velocity point measurements with an impeller flowmeter during a pumping test, adapted from Read et al. [2014]. The "processed" $\Delta T$ profile is the result of a moving median filter applied to the original data in order remove the local effect of the cable centralizers used in the deployment. hybrid cable log also suffered from some artifacts due to cable deployment. Where the cable touched the wall, at around $60 \mathrm{~m}$ depth, the $\Delta T$ value was higher. The presence of other objects inside the well, in this case $2 \mathrm{~m}$ spaced plastic centralizers to keep the heated cable in the center of the borehole, caused localized cooling thought to be due to the stimulation of vortices enhancing the heat transfer from cable to borehole fluid.

The hybrid cable approach has the advantage that it is possible to monitor time varying velocity and flow changes more readily than with point thermal advection tests. However, since the response is sensitive to anything altering the efficiency of heat transfer from the cable, effects due to varying cable centralization or other instrumentation in the well disturbing the flow may be apparent. It is also likely to require empirical calibration in the field and for each well prior to use.

\subsection{Heat Pulse Tests}

Apparent thermal properties along a wellbore can be characterized using DTS heat pulse tests. This method is based on applying a constant power output over the entire deployed cable length for a period of time and monitoring the heating and/or cooling phases using DTS [Coleman et al., 2015; Hausner et al., 2015; Seibertz et al., 2016]. The measured thermal response is dependent on both conductive and advective components of heat transfer. Through careful analysis information regarding both lithological variations and natural gradient flow distributions can be gathered.

In heat pulse tests, heating or cooling data may be used. An analytical solution exists for constant heat injection in a homogeneous, radially symmetric porous medium. This is given by Shen and Beck [1986]:

$$
k_{a}=\frac{Q}{4 \pi} \cdot \frac{\ln \left(t_{2} / t_{1}\right)}{T_{2}-T_{1}}
$$

where $k_{a}\left[\mathrm{~W} \mathrm{~m}{ }^{-1} \mathrm{~K}^{-1}\right]$ is the apparent thermal conductivity of the formation, $Q\left[\mathrm{~W} \mathrm{~m} \mathrm{~m}^{-1}\right]$ is again electrical power input, and $T_{1}$ and $T_{2}$ are the temperatures at times $t_{1}$ and $t_{2}$, respectively. Heat Pulse Tests can be conducted using either separate heating and fiber optic cables or with a composite cable that incorporates both resistance heating wires and optical fibers. Early installations [e.g., Freifeld et al., 2008], utilized separate cables for heating and temperature measurements in which the distance between these cables is variable with depth. Temperature measurements during heating are highly dependent on the distance between the heating wires and optical fibers; thus, cooling data were exclusively used for data analysis where distance variations had much less of an effect. The application of composite cables has allowed for both heating and cooling data to be analyzed [Coleman et al., 2015; Hausner et al., 2015]; however, cable materials and geometry as well as installation geometry still play a major role in the measured response and is an area of ongoing research. For example, variable cable coupling between the rock formation and wellbore fluids can negatively impact the measurement response. Care must be taken when applying equation (2) for composite cables. The initial temperature increase will be due to the thermal properties of the cable, so late time data must be used. Detailed numerical modeling can be used to assess in more details the relevance of these various complicating factors for the interpretation of A-DTS data sets [Hausner et al., 2015].

Since heat pulse tests measure apparent thermal properties, specific information regarding the field installation is required if isolating the conductive and advective components of heat transfer is desired. Freifeld et al. [2008] deployed cable inside a $535 \mathrm{~m}$ deep borehole through volcanic strata in a permafrost environment, and used a 1-D radial model to invert cooling data from a heat pulse test to determine a thermal conductivity profile. In this case, both natural gradient flow and vertical wellbore flow variations were assumed to be negligible in order to 


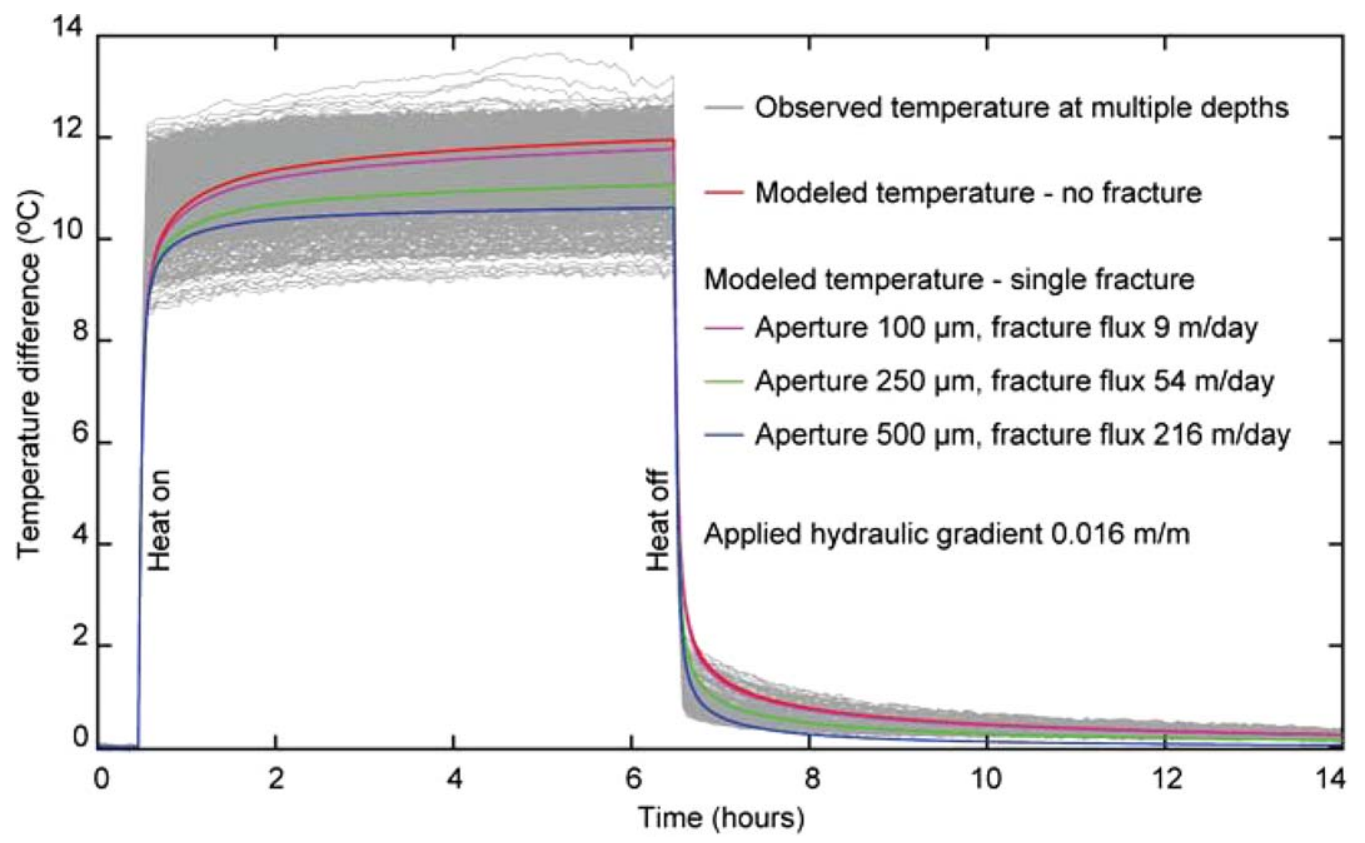

Figure 7. Field data from a borehole heat pulse test in a borehole with strongly varying groundwater influxes [Coleman et al., 2015]. Field data show a wide range of responses and models have been used to provide an initial indication over which range the these fluxes would vary to understand the observed varaibility is DTS measured responses and hence the sensitivity of the measurements to the groundwater influx.

calculate thermal conductivity profiles. If the thermal properties of the rock strata are known there is significant potential for using apparent thermal data to quantify flow [Coleman et al., 2015]. Figure 7 highlights the modeled effect of flow on Heat Pulse temperature data in comparison with field data collected in a dolostone aquifer. Differentiating natural gradient groundwater flow from lithological variations remains challenging. To determine lithological changes, groundwater flow must be known or assumed; whereas, to isolate groundwater flow thermal properties of the rock must be known a priori. In either case the borehole should be cased or sealed using a flexible borehole liner to eliminate cross-connected wellbore flow that would cause significant measurement bias.

\section{Future Developments}

Both the hybrid cable and heat pulse methods are at a relatively early stage of development in hydrogeological applications. While in oil and gas studies similar methods are already more widely applied [Bolognini and Hartog, 2013] they are mostly used as qualitative monitoring solutions. The main development to be looking forward to is to make downhole DTS methods into tools from which quantitative data can be gathered on hydrogeological conditions outside the borehole. Numerical modeling can be expected to be an important route in this process as they can consider the complex geometries associated with borehole installations and its impact on the strongly coupled fluid and heat flow processes associated with (A-)DTS experiments. Such simulations should be used to assess and quantitatively interpret DTS data sets for hydrogeologically relevant parameters (e.g., formation groundwater flow). Moreover, prior to field installations they can serve to trial the large range of options for deployment (e.g., configuration of the cable in the system, optimum A-DTS heat input) that many current researchers are so creatively exploring. This is critical since, as we have shown in this review, all of the choices associated with the design of a downhole DTS deployment will impact the effectiveness of DTS in obtaining valid and valuable data.

While there are many literature examples of subsurface DTS application, there is plenty of opportunity for future development of the technology in groundwater studies as instrument and cable performance improve. Further work is also needed to assess the sensitivity of active methods under different conditions to both in-well vertical flow and natural gradient flow, and turn them into readily deployable monitoring solutions providing quantitative results. In order to do this auxiliary data are needed to complement DTS data sets. Spatially distributed data like DTS are likely to originate from other hydrogeophysical methods which are still actively developed [Binley et al., 2015]. DTS can be combined with such methods like it is 
with, for example, with Distributed Acoustic Sensing which is another optical-fiber sensing method [Noni et al., 2011; Mondanos et al., 2015].

\section{Conclusion}

Our overview has highlighted examples where DTS has been used in studies of aquifer heterogeneity, groundwater flow, subsurface heat transport, and geothermal and $\mathrm{CO}_{2}$ sequestration. Such deployments are typically either passive or active. In passive applications, DTS can provide near real time temperature monitoring, simultaneously, potentially in multiple deep wells at high spatial resolution. This allows dynamic processes to be monitored in detail, and long data sets to be efficiently collected. Active DTS methods aim to primarily measure in-well flow (thermal advection tests and hybrid cable flow measurements), and thermal properties and natural gradient groundwater flow (heat pulse tests). While there are some similarities between the active methods, it is important to note the differences in the sensitivities of each method and the underlying physics. When considering undertaking field or laboratory experiments active and passive methods may easily be combined to efficiently obtain different but complementary data. For instance, after heating a cable for a long duration, it may be possible after hybrid cable flow logging to monitor the return of the slightly warmed borehole to background temperature. The first measurements would give flow in the well, while the second may yield information on aquifer heterogeneity and thermal properties.

When to use DTS in a borehole setting requires careful consideration. If there is a passive process to be monitored with either little time or depth variability, then a log obtained with a high temperature resolution temperature probe, or a time series from a data logger at a particular depth might yield equivalent or better data sets with less effort. However, DTS is proving invaluable in applications where there is significant time and depth variability. Here the required effort in terms of installation of power supply, calibration baths, and the postprocessing of the data should far be outweighed by the benefits to hydrogeological research provided by the wealth of additional detail in spatiotemporal temperature dynamics recorded by DTS.

\section{Acknowledgments}

Thomas Coleman's contribution was made possible in part by data and ongoing research from the University of Guelph, G360 Centre for Applied Groundwater Research (Ontario, Canada). We thank the editorial team, Associate Editor Andrew Binley, Reviewer Nick van de Giesen, and two anonymous Reviewers for their time and energy spend to provide constructive feedback on earlier versions of this manuscript. Funding for this work was provided by a Natural Environment Research Council (NERC) studentship (NE/J500069/1) to Tom Read. Some of the data come from the national network of hydrogeological sites $\mathrm{H}+$. The ANR project CRITEX ANR-11-EQPX-0011 provided partial funding for Olivier Bour and Tanguy Le Borgne. John Selkers contributions to this work were made possible by grants from the US government via NASA award NNX12AP58G and the Center for Transformative Environmental Monitoring Programs (CTEMPs) funded by the National Science Foundation, award EAR 0930061. Data underlying this study can be obtained upon request from the corresponding author (victor.bense@wur.nl).

\section{References}

Arnon, A., N. G. Lensky, and J. S. Selker (2014a), High-resolution temperature sensing in the dead sea using fiber optics, Water Resour. Res. 50, 1756-1772, doi:10.1002/2013WR014935.

Arnon, A., J. Selker, and N. Lensky (2014b), Correcting artifacts in transition to a wound optic fiber: Example from high-resolution temperature profiling in the dead sea, Water Resour. Res., 50, 5329-5333, doi:10.1002/2013WR014910.

Aufleger, M., M. Conrad, M. Goltz, S. Perzlmaier, and P. Porras (2007), Innovative dam monitoring tools based on distributed temperature measurement, Jordan J. Civ. Eng., 1(1), 29-37.

Bakker, M., R. Caljé, F. Schaars, K.-J. van der Made, and S. de Haas (2015), An active heat tracer experiment to determine groundwater velocities using fiber optic cables installed with direct push equipment, Water Resour. Res., 51, 2760-2772, doi:10.1002/2014WR016632.

Banks, E. W., M. A. Shanafield, and P. G. Cook (2014), Induced temperature gradients to examine groundwater flowpaths in open boreholes, Ground Water, 52(6), 943-951, doi:10.1111/gwat.12157.

Bense, V. F., and H. Kooi (2004), Temporal and spatial variations of shallow subsurface temperature as a record of lateral variations in groundwater flow, J. Geophys. Res., 109, B04103, doi:10.1029/2003JB002782.

Bense, V. F., M. Person, K. Chaudhary, Y. You, N. Cremer, and S. Simon (2008), Thermal anomalies as indicator of preferential flow along faults in an unconsolidated sedimentary aquifer system, Geophys. Res. Lett., 35, L24406, doi:10.1029/2008GL036017.

Binley, A., S. S. Hubbard, J. A. Huisman, A. Revil, D. A. Robinson, K. Singha, and L. D. Slater (2015), The emergence of hydrogeophysics for improved understanding of subsurface processes over multiple scales, Water Resour. Res., 51, 3837-3866, doi:10.1002/2015WR017016.

Bolognini, G., and A. Hartog (2013), Raman-based fibre sensors: Trends and applications, Opt. Fiber Technol., 19(6, Part B), 678-688, doi: 10.1016/j.yofte.2013.08.003.

Bredehoeft, J. D., and I. S. Papadopulos (1965), Rates of vertical groundwater movement estimated from the earth's thermal profile, Water Resour. Res., 1(2), 325-328, doi:10.1029/WR001i002p00325.

Briggs, M. A., L. K. Lautz, and J. M. McKenzie (2012a), A comparison of fibre-optic distributed temperature sensing to traditional methods of evaluating groundwater inflow to streams, Hydrol. Processes, 26(9), 1277-1290, doi:10.1002/hyp.8200.

Briggs, M. A., L. K. Lautz, J. M. McKenzie, R. P. Gordon, and D. K. Hare (2012b), Using high-resolution distributed temperature sensing to quantify spatial and temporal variability in vertical hyporheic flux, Water Resour. Res., 48, W02527, doi:10.1029/2011WR011227.

Cao, D., B. Shi, H. Zhu, K. Zhu, G. Wei, and K. Gu (2015), Performance evaluation of two types of heated cables for distributed temperature sensing-based measurement of soil moisture content, J. Rock Mech. Geotechn. Eng., 8(2), 212-217, doi:10.1016/j.jrmge.2015.09.005.

Coleman, T. I., B. L. Parker, C. H. Maldaner, and M. J. Mondanos (2015), Groundwater flow characterization in a fractured bedrock aquifer using active $\{$ DTS $\}$ tests in sealed boreholes, J. Hydrol., 528, 449-462, doi:10.1016/j.jhydrol.2015.06.061.

Conant, B. (2004), Delineating and quantifying ground water discharge zones using streambed temperatures, Ground Water, 42(2), $243-257$.

Dakin, J. P., D. J. Pratt, G. W. Bibby, and J. N. Ross (1985), Distributed optical fibre Raman temperature sensor using a semiconductor light source and detector, Electron. Lett., 21(13), 569-570.

Drury, M., A. Jessop, and T. Lewis (1984), The detection of groundwater flow by precise temperature measurements in boreholes, Geothermics, 13(3), 163-174, doi:10.1016/0375-6505(84)90013-0.

Edwards, S., C. Coley, M. Edwards, D. Shafer, and M. Alberty (2010), Method of determining borehole conditions from distributed measurement data, WO Patent App. PCT/US2009/056,986, BP Exploration Operating Company Limited, London, U. K. 
Farahani, M., and T. Gogolla (1999), Spontaneous Raman scattering in optical fibers with modulated probe light for distributed temperature Raman remote sensing, J. Lightwave Technol., 17(8), 1379-1391, doi:10.1109/50.779159.

Foerster, A., J. Schroetter, D. F. Merriam, and D. D. Blackwell (1997), Application of optical-fiber temperature logging; an example in a sedimentary environment, Geophysics, 62(4), 1107-1113, doi:10.1190/1.1444211.

Freifeld, B. M., S. Finsterle, T. C. Onstott, P. Toole, and L. M. Pratt (2008), Ground surface temperature reconstructions: Using in situ estimates for thermal conductivity acquired with a fiber-optic distributed thermal perturbation sensor, Geophys. Res. Lett., 35, L14309, doi: $10.1029 / 2008 \mathrm{GL} 034762$.

$\mathrm{Ge}$, S. (1998), Estimation of groundwater velocity in localized fracture zones from well temperature profiles, J. Volcanol. Geotherm. Res., 84 , 93-101, doi:10.1016/S0377-0273(98)00032-8.

Grosswig, S., E. Hurtig, and K. Kuehn (1996), Fibre optic temperature sensing; a new tool for temperature measurements in boreholes, Geophysics, 61(4), 1065-1067, doi:10.1190/1.1444027.

Guan, B.-O., J. Li, L. Jin, and Y. Ran (2013), Fiber Bragg gratings in optical microfibers, Opt. Fiber Technol., 19(6, Part B), 793-801, doi:10.1016/ j.yofte.2013.07.007.

Hare, D. K., M. A. Briggs, D. O. Rosenberry, D. F. Boutt, and J. W. Lane (2015), A comparison of thermal infrared to fiber-optic distributed temperature sensing for evaluation of groundwater discharge to surface water, J. Hydrol., 530, 153-166, doi:10.1016/j.jhydrol.2015.09.059.

Hausner, M. B., and S. Kobs (2016), Identifying and correcting step losses in single-ended fiber-optic distributed temperature sensing data, J. Sensors, 2016, ID 7073619, 10 pp., doi:10.1155/2016/7073619.

Hausner, M. B., F. Suárez, K. E. Glander, N. V. D. Giesen, J. S. Selker, and S. W. Tyler (2011), Calibrating single-ended fiber-optic Raman spectra distributed temperature sensing data, Sensors, 11, 10,859-10,879, doi:10.3390/s111110859.

Hausner, M. B., L. Kryder, J. Klenke, R. Reinke, and S. W. Tyler (2015), Interpreting variations in groundwater flows from repeated distributed thermal perturbation tests, Ground Water, 54(4), 559-568, doi:10.1111/gwat.12393.

Hawkins, A. J., and M. W. Becker (2012), Measurement of the spatial distribution of heat exchange in a geothermal analog bedrock site using fiber optic distributed temperature sensing, in Proceedings Thirty-Seventh Workshop on Geothermal Reservoir Engineering, Stanford, California, January, 2012.

Henninges, J., J. Schrötter, K. Erbas, S. Böde, and E. Huenges (2003), Permanent installation of fibre-optic DTS cables in boreholes for temperature monitoring, in EGS-AGU-EUG Joint Assembly, pp. 11394., Abstracts from the meeting held in Nice, France, 6-11 April 2003.

Henninges, J., E. Huenges, and H. Burkhardt (2005), In situ thermal conductivity of gas-hydrate-bearing sediments of the mallik $5 \mathrm{l}-38$ well, J. Geophys. Res., 110, B11206, doi:10.1029/2005JB003734.

Hermans, T., S. Wildemeersch, P. Jamin, P. Orban, S. Brouyère, A. Dassargues, and F. Nguyen (2015), Quantitative temperature monitoring of a heat tracing experiment using cross-borehole ERT, Geothermics, 53, 14-26, doi:10.1016/j.geothermics.2014.03.013.

Hilgersom, K., T. van Emmerik, A. Solcerova, W. Berghuijs, J. Selker, and N. van de Giesen (2016), Practical considerations for enhancedresolution coil-wrapped distributed temperature sensing, Geosci. Instrum. Methods Data Syst., 5(1), 151-162, doi:10.5194/gi-5-151-2016.

Hurtig, E., S. Grosswig, and K. Kuhn (1996), Fibre optic temperature sensing: application for subsurface and ground temperature measurements, Tectonophysics, 257, 101-109.

Ikeda, N., K. Uogata, K. Seiki, and K. Haruguchi (2000), Delineation of fractured reservoir by transient temperature analysis using fiber optic sensor, in Proceedings World Geothermal Congress, 2617-2621, Kyushu-Tokuhu, Japan.

Klepikova, M. V., T. L. Borgne, O. Bour, and P. Davy (2011), A methodology for using borehole temperature-depth profiles under ambient, single and cross-borehole pumping conditions to estimate fracture hydraulic properties, J. Hydrol., 407, 145-152, doi:10.1016/ j.jhydrol.2011.07.018.

Klepikova, M. V., T. L. Borgne, O. Bour, K. Gallagher, R. Hochreutener, and N. Lavenant (2014), Passive temperature tomography experiments to characterize transmissivity and connectivity of preferential flow paths in fractured media, J. Hydrol., 512, 549-562, doi:10.1016/ j.jhydrol.2014.03.018.

Kurth, A.-M., N. Dawes, J. Selker, and M. Schirmer (2013), Autonomous distributed temperature sensing for long-term heated applications in remote areas, Geosci. Instrum. Methods Data Syst., 2(1), 71-77, doi:10.5194/gi-2-71-2013.

Leaf, A. T., D. J. Hart, and J. M. Bahr (2012), Active thermal tracer tests for improved hydrostratigraphic characterization, Ground Water, 50(5), 726-735, doi:10.1111/j.1745-6584.2012.00913.x.

Liu, G., S. Knobbe, and J. Butler (2013), Resolving centimeter-scale flows in aquifers and their hydrostratigraphic controls, Geophys. Res. Lett., 40, 1098-1103, doi:10.1002/grl.50282.

Macfarlane, A., A. Förster, D. Merriam, J. Schrötter, and J. Healey (2002), Monitoring artificially stimulated fluid movement in the Cretaceous Dakota aquifer, western Kansas, Hydrogeol. J., 10(6), 662-673, doi:10.1007/s10040-002-0223-7.

Mondanos, M., T. Parker, C. H. Milne, J. Yeo, T. Coleman, and M. Farhadiroushan (2015), Distributed temperature and distributed acoustic sensing for remote and harsh environments, in Sensors for Extreme Harsh Environments II, Proceedings of SPIE, edited by D. G. Senesky, and S. Dekate, vol. 9491, SPIE, Baltimore, Md., doi:10.1117/12.2179504.

Noni, N., M. M. MacLaughlin, and H. F. Wang (2011), Validation of fiber-optic strain sensing cable for deep underground installation, in 45th U.S Rock Mechanics, 8 pp., American Rock Mechanics Association, San Francisco, Calif.

Pehme, P., B. Parker, J. Cherry, J. Molson, and J. Greenhouse (2013), Enhanced detection of hydraulically active fractures by temperature profiling in lined heated bedrock boreholes, J. Hydrol., 484, 1-15, doi:10.1016/j.jhydrol.2012.12.048.

Rahman, M., P. J. Zannitto, D. A. Reed, and M. E. Allan (2011), Application of fiber-optic distributed temperature sensing technology for monitoring injection profile in belridge field, diatomite reservoir, paper presented SPE Digital Energy Conference and Exhibition, 19-21 April, The Woodlands, Texas, Soc. of Petrol. Eng., doi:10.2118/144116-MS.

Read, T., O. Bour, V. Bense, T. Le Borgne, P. Goderniaux, M. Klepikova, R. Hochreutener, N. Lavenant, and V. Boschero (2013), Characterizing groundwater flow and heat transport in fractured rock using fiber-optic distributed temperature sensing, Geophys. Res. Lett., 40, 20552059, doi:10.1002/grl.50397.

Read, T., O. Bour, J. S. Selker, V. F. Bense, T. L. Borgne, R. Hochreutener, and N. Lavenant (2014), Active-distributed temperature sensing to continuously quantify vertical flow in boreholes, Water Resour. Res., 50, 3706-3713, doi:10.1002/2014WR015273.

Read, T., V. F. Bense, O. Bour, T. Le Borgne, N. Lavenant, R. Hochreutener, and J. S. Selker (2015), Thermal-plume fibre optic tracking (t-pot) test for flow velocity measurement in groundwater boreholes, Geosci. Instrum. Methods Data Syst. Discuss., 5(1), 161-175, doi:10.5194/gid-5-161-2015.

Reinsch, T., J. Henninges, and R. Ásmundsson (2013), Thermal, mechanical and chemical influences on the performance of optical fibres for distributed temperature sensing in a hot geothermal well, Environ. Earth Sci., 70(8), 3465-3480, doi:10.1007/s12665-013-2248-8.

Rogers, A. (1999), Distributed optical-fibre sensing, Measur. Sci. Technol., 10(8), R75-R99.

Saar, M. O. (2011), Review: Geothermal heat as a tracer of large-scale groundwater flow and as a means to determine permeability fields, Hydrogeol. J., 19(1), 31-52. 
Sakaguchi, K., and N. Matsushima (2000), Temperature logging by the distributed temperature sensing technique during injection tests, Proceedings World Geothermal Congress, Kyushy-Tohoku, Japan.

Sayde, C., C. K. Thomas, J. Wagner, and J. Selker (2015), High-resolution wind speed measurements using actively heated fiber optics, Geophys. Res. Lett., 42, 10,064-10,073, doi:10.1002/2015GL066729.

Schuetz, T., and M. Weiler (2011), Quantification of localized groundwater inflow into streams using ground-based infrared thermography, Geophys. Res. Lett., 38, L03401, doi:10.1029/2010GL046198.

Seibertz, K. S. O., M. A. Chirila, J. Bumberger, P. Dietrich, and T. Vienken (2016), Development of in-aquifer heat testing for high resolution subsurface thermal-storage capability characterisation, J. Hydrol., 534, 113-123, doi:10.1016/j.jhydrol.2015.12.013.

Selker, J. S., et al. (2006), Distributed fiber-optic temperature sensing for hydrologic systems, Water Resour. Res., 42, W12202, doi:10.1029/ 2006 WR005326.

Selker, J. S., S. Tyler, and N. van de Giesen (2014), Comment on "capabilities and limitations of tracing spatial temperature patterns by fiber-optic distributed temperature sensing" by Liliana rose et al., Water Resour. Res., 50, 5372-5374, doi:10.1002/2013WR014979.

Sellwood, S., D. Hart, and J. Bahr (2015a), An in-well heat-tracer-test method for evaluating borehole flow conditions, Hydrogeol. J., 23(8), 1817-1830, doi:10.1007/s10040-015-1304-8.

Sellwood, S. M., D. J. Hart, and J. M. Bahr (2015b), Evaluating the use of in-well heat tracer tests to measure borehole flow rates, Ground Water Monit. Rem., 35, 85-94, doi:10.1111/gwmr.12134.

Shen, P., and A. Beck (1986), Stabilization of bottom hole temperature with finite circulation time and fluid flow, Geophys. J. Int., 86, 63-90. Smolen, J. J., and A. van der Spek (2003), A dts primer for oil and gas production, Tech. Rep. EP 2003-7100, Shell Int. Explor. and Prod. B.V., The Hague, Netherlands.

Stotler, R. L., S. K. Frape, B. M. Freifeld, B. Holden, T. C. Onstott, T. Ruskeeniemi, and E. Chan (2011), Hydrogeology, chemical and microbial activity measurement through deep permafrost, Ground Water, 49(3), 348-364, doi:10.1111/j.1745-6584.2010.00724.x.

Taniguchi, M. (1993), Evaluation of vertical groundwater fluxes and thermal properties of aquifers based on transient temperature-depth profiles, Water Resour. Res., 29(7), 2021-2026, doi:10.1029/93WR00541.

Tyler, S. W., J. S. Selker, M. B. Hausner, C. E. Hatch, T. Torgersen, C. E. Thodal, and S. G. Schladow (2009), Environmental temperature sensing using Raman spectra DTS fiber-optic methods, Water Resour. Res., 45, W00D23, doi:10.1029/2008WR007052.

Van De Giesen, N., S. C. Steele-Dunne, J. Jansen, O. Hoes, M. B. Hausner, S. Tyler, and J. Selker (2012), Double-ended calibration of fiberoptic Raman spectra distributed temperature sensing data, Sensors, 12(5), 5471-5485.

Vogt, T., P. Schneider, L. Hahn-Woernle, and O. A. Cirpka (2010), Estimation of seepage rates in a losing stream by means of fiber-optic high-resolution vertical temperature profiling, J. Hydrol., 380, 154-164, doi:10.1016/j.jhydrol.2009.10.033.

Wagner, V., T. Li, P. Bayer, C. Leven, P. Dietrich, and P. Blum (2014), Thermal tracer testing in a sedimentary aquifer: Field experiment (Lauswiesen, Germany) and numerical simulation, Hydrogeol. J., 22(1), 175-187, doi:10.1007/s10040-013-1059-z.

Wisian, K. W., D. D. Blackwell, S. Bellani, J. A. Henfling, R. A. Normann, P. C. Lysne, A. Förster, and J. Schrötter (1998), Field comparison of conventional and new technology temperature logging systems, Geothermics, 27(2), 131-141, doi:10.1016/S0375-6505(97)10013-X.

Yamano, M., and S. Goto (2005), Long-term monitoring of the temperature profile in a deep borehole: Temperature variations associated with water injection experiments and natural groundwater discharge, Phys. Earth Planet. Inter., 152(4), 326-334, doi:10.1016/j.pepi. 2005.04.010 